\title{
Interdependence of the peripheral metabolism of glucocorticoids and thyroid hormones under calorie deficit in rats at different ages
}

\author{
M. Stachoń, J. Gromadzka-Ostrowska, K. Lachowicz', E. Fürstenberg, E. Pałkowska, D. Gajewska, \\ J. Myszkowska-Ryciak, L. Kozłowska and D. Rosołowska-Huszcz \\ Warsaw University of Life Sciences - SGGW, Department of Dietetics, Faculty of Human Nutrition and Consumer Sciences \\ Nowoursynowska 159c, 02-776 Warsaw, Poland
}

KEY WORDS: glucocorticoids, glucocorticoid receptors, type $111 \beta$-hydroxylase, type $111 \beta$-hydroxysteroid dehydrogenase, deiodinases, energy deficit, rats
Received: 25 November 2013

Revised: 3 January 2014

Accepted: 12 June 2014

\begin{abstract}
The joint effects of energy restriction and age on adrenal glucocorticoid synthesis, liver signalling and liver thyroid hormone metabolism were examined. Adrenal type $111 \beta$-hydroxylase expression was chosen as a marker of adrenal steroidogenesis, liver 11ß-hydroxysteroid dehydrogenase 1 and glucocorticoid receptor proteins as measures of glucocorticoid signalling, and liver type 1 and 3 deiodinase proteins as determinants of thyroid hormone metabolism. A nine-week study covered two groups ( $n=21$ each) of 17 - and 45-week-old Sprague-Dawley male rats fed ad libitum and on diets with $20 \%$ or $40 \%$ energy deficit. Adrenal type $111 \beta$-hydroxylase mRNA and protein, hepatic type $111 \beta$-hydroxysteroid dehydrogenase level, glucocorticoid receptor and type 1 and 3 deiodinase protein levels, as well as plasma adrenocorticotropic hormone $(A C T H)$ and corticosterone concentrations. Calorie restriction increased ACTH plasma concentrations and type $111 \beta$-hydroxylase protein levels were determined. Plasma ACTH and type $111 \beta$-hydroxylase protein were higher in older rats, while in the younger group, type 1 deiodinase protein exceeded the enzyme level in older rats. Calorie restriction decreased plasma corticosterone and type $111 \beta$-hydroxysteroid dehydrogenase only in older rats. Direct relationships between glucocorticoid receptors and type 1 and 3 deiodinases, as well as between type 3 deiodinase and type $111 \beta$-hydroxysteroid dehydrogenase, were observed. Taken together, the results indicate that responses of the rat pituitary-adrenal axis to calorie deficit are age-dependent. Moreover, the observed correlations suggest a mechanism linking an increase in glucocorticoid receptors with a reduction in peripheral thyroid hormone action resulting from a rise in the level of type 3 deiodinase.
\end{abstract}

${ }^{1}$ Corresponding author:

e-mail: katarzyna_lachowicz@sggw.pl and interconversion leading to activation or in activation in peripheral tissues. One of the organs involved is the liver, which expresses both $11 \beta$-hydroxysteroid dehydrogenase (11 $\beta$-HSD) as well as type 1 (DIO1) and type 3 iodothyronine deiodinases (DIO3) (Bianco et al., 2002). 
Glucocorticoids are synthesized in the adrenal cortex from cholesterol via a series of reactions that are catalysed by several steroid hydroxylases (members of the cytochrome P450 superfamily, P450s) and $3 \beta$-hydroxysteroid dehydrogenase. In the first enzymatic process, which occurs in mitochondria, cholesterol side-chain-cleavage monooxygenase (P450 11A1, P450scc) catalyses 20 $\alpha$ and $22 \alpha$-hydroxylations and C20,22-bond scission to convert 27-carbon cholesterol to 21-carbon pregnenolone. The final reaction in adrenocortical steroidogenesis also occurs in mitochondria where 11-deoxycortisol and deoxycorticosterone are converted by $11 \beta$-hydroxylase (CYP11B1) to cortisol and corticosterone (Cs), respectively (Sewer et al., 2007).

The effects of glucocorticoids on target tissues are mediated mainly by type 2 glucocorticoid receptors (GRs). The level of GR expression is one of the principal determinants of sensitivity to GCs and, in transgenic mice, both reduced and increased GR levels alter glucocorticoid signalling with pathophysiological consequences (Adcock et al., 2006; Kharwanlang and Sharma, 2011). The intracellular concentrations of GCs, and thus the activation of their receptors, are regulated by the activity of $11 \beta-\mathrm{HSD}$ - a microsomal enzyme complex responsible for the interconversion of cortisol/corticosterone and hormonally inactive cortisone/11 $\beta$-dehydrocorticosterone. There are at least two isoforms of $11 \beta$-HSD. Type $111 \beta$-HSD (11 $\beta$-HSD1), an $\mathrm{NADP}^{+}$-dependent isoform, catalyses both the oxidation of cortisol/corticosterone into cortisone/11 $\beta$-dehydrocorticosterone and the reduction of cortisone/11 $\beta$-dehydrocorticosterone into cortisol/ corticosterone. $11 \beta$-HSD1 plays an important role in enhancing GR activation. Type $211 \beta-H S D$ (11ß-HSD2), an $\mathrm{NAD}^{+}$-dependent isoform, catalyses only the oxidation of cortisol/corticosterone to cortisone $/ 11 \beta$ dehydrocorticosterone (Seckl, 2004; Tomlinson et al., 2004). Alterations in 11 $\beta$-HSD activities have been associated with several human diseases, including hypertension, diabetes, obesity, metabolic syndrome, atherosclerosis, age-related cognitive dysfunction, osteoporosis, arthritis, and many others (Aguilera, 2011).

Studies on the nutritional regulation of $11 \beta$-HSD1 have focused on the effects of lipidogenic diets (Morton et al., 2004; London and Castonguay, 2011; Auvinen et al., 2012; Fernando et al., 2013), dietaryinduced obesity and weight reduction treatment (London and Castonguay, 2009; Simonyte et al., 2010; Rask et al., 2013), as well as of food restriction on 11ß-HSD-1 in adipose tissue (Arai et al., 2004). To our knowledge, the effect of calorie restriction on $11 \beta$-HSD1 expression in the liver has not been investigated as yet.
Thyroid hormones are deiodinated in target tissues by type 1,2, and 3 iodothyronine deiodinases. Type 1 deiodinase catalyses both 5' and 5 deiodination, type 2 deiodinase (DIO2) removes iodide from 5 ' iodothyronine position, and type 3 deiodinase deiodinates iodothyronine in position 5 . Thyroxine $\left(3,3^{\prime}, 5,5^{\prime}\right.$ 'tetraiodothyronine, $\left.T 4\right)$ deiodinated in position 5' turns into metabolically active 3,3', 5 triiodothyronine (T3), while T4 deiodinated in position 5 becomes metabolically inert 3,3',5' triiodothyronine (reverse triiodothyronine - rT3). Under normal conditions, liver deiodination is based on DIO1 action and is responsible for the delivery of circulating T3 (Bianco et al., 2002).

Calorie or energy restriction commonly refers to the lowering of calorie intake without a reduction in protein and micronutrients essential for normal growth and development. Various laboratories have shown that calorie restriction (CR) significantly extends the life span in different groups of animals. Some of the effects of dietary restriction, such as protection against insulin-dependent diabetes in rodents, anti-inflammatory and antineoplastic effects, neurological impairments, and reproductive senescence, are parallel to the consequences of elevated levels of GCs (Sharma and Dutta, 2006). During calorie restriction, a decrease in thyroid activity, coupled with a decrease in liver 5'deiodination and an increase in 5 deiodination, among others, has been observed. Both a switch in DIO1 activity from 5' to 5 deiodination and an increase in liver DIO3 activity have been postulated (Bianco et al., 2002).

Although the hormonal effects of calorie restriction have been thoroughly explored, the combined effects of CR and age on glucocorticoid synthesis and their liver signalling together with liver thyroid hormone metabolism have not been hitherto elucidated. Therefore, the aim of our study was to examine concurrently the effect of energy restriction and age on adrenal CYP11B1 as an important enzyme in adrenal steroidogenesis, liver $11 \beta$-HSD1 and GRs as markers of GC signalling, as well as liver DIO1 and DIO3 as determinants of $\mathrm{TH}$ metabolism.

\section{Material and methods}

\section{Animals and treatment}

The present paper is the second report from an experiment whose results were described previously (Lachowicz et al., 2014). The 9-week experiment was performed on 42 adult male Sprague-Dawley rats obtained from the Mossakowski Medical 
Research Centre, Polish Academy of Science, Warsaw (Poland). The rats were divided into 2 groups (21 rats each): a younger group (A), i.e. 17-weekold males with an initial body weight (BW) of 442.2 $\pm 35.3 \mathrm{~g}$, and an older group (B), i.e. 45-week-old males with an initial BW of $594.4 \pm 42.3 \mathrm{~g}$. After an adaptation period, both groups were assigned to 3 dietary subgroups (7 individuals each). Groups $\mathrm{AL}$ and $\mathrm{BL}$ were fed ad libitum on a standard diet (V1320-000, SSNIFF Spezialdiäten GmbH, Germany) containing $21.2 \%$ protein, $3.8 \%$ fat, $70.6 \%$ carbohydrates and $4.4 \%$ fibre. The other animals (groups AR20, AR40, BR20, BR40) were subjected to energy restriction (R). At the beginning of the experiment, energy intake was set at $20 \%$ (R20) and $40 \%$ (R40) energy restriction based on ad libitum intakes during the adaptation period. The energetic value of $\mathrm{R}$ rations was reduced by diminishing the content of carbohydrates and fat. R20 and R40 diets were supplemented with protein (casein), vitaminmineral mixture (R122F002, SSNIFF Spezialdiäten $\mathrm{GmbH}$, Germany) to the AL/BL ingredient intakes. Feed intakes of $\mathrm{R}$ rats were updated to energy intakes of AL/BL rats on a weekly basis. Feed consumption of all groups was measured every day and the animals were weighed weekly. All rats had free access to fresh water throughout the experiment.

Housing conditions included individual cages, 12-h light/dark cycle, temperature of $22^{\circ} \mathrm{C}$ and relative humidity of $60 \%$. The animals were reared and handled in accordance with protocols approved by the Local Animal Care and Use Committee (Warsaw University of Life Sciences, Poland).

Following the experiment, the rats were fasted overnight and anaesthetized by isoflurane inhalation. Blood was collected from the heart into EDTA-ised vacutainer tubes and subsequently centrifuged (4000 $\mathrm{rpm}, 4^{\circ} \mathrm{C}, 15 \mathrm{~min}$ ). Plasma was stored at $-23^{\circ} \mathrm{C}$ until analysis. Both adrenals and liver were excised, one adrenal was sampled, immersed in RNAlater, and stored for determination of gene expression. The second adrenal and pieces of the liver were snap frozen in liquid nitrogen. All samples were stored at $-80^{\circ} \mathrm{C}$ until molecular and cellular analysis.

\section{Adrenal CYP11B1 expression}

Total RNA was isolated from adrenal samples using a total RNA kit (A\&A Biotechnology, Poland) according to the manufacturer's protocol. Isolated RNA samples were dissolved in RNAase-free water, and RNA quantity was measured with the use of NanoDrop (NanoDrop Technologies, USA). Samples with adequate amounts of RNA were treated with TURBO DNAase (Applied Biosystems, USA) to eliminate DNA contamination. Subsequently, TURBO DNAase was inactivated by means of phenol/chloroform extraction (Invitrogen, USA), as instructed by the manufacturer. The samples were analysed again with a BioAnalyzer (Agilent, USA) to measure final RNA quality and integrity. Total RNA $(0.1 \mu \mathrm{g})$ was reverse-transcribed using High Capacity RNA-to-cDNA Master Mix (Applied Biosystems, USA).

Expression of the CYP11B1 gene was analysed by real-time TaqMan PCR, TaqMan Univesal PCR Master Mix (Applied Biosystems, USA). The reaction mix contained $0.1 \mu \mathrm{g}$ of cDNA and Rn02607234_g1, VIC-labelled TaqMan probe for CYP11B1 designed by Applied Biosystems, USA). Additionally, three endogenous controls were used: Rat GAPDH, VIClabelled, Rat ACTB, FAM-labelled, and Rat Ubc, FAM-labelled (cat \# 4352338E, cat \# 4352931E, and Rn01499642_m1, respectively; Applied Biosystems, USA). TaqMan PCR was performed using a Stratagene Mx3005P QPCR System (Agilent Technologies, USA) with the initial incubation at $50^{\circ} \mathrm{C}$ for $2 \mathrm{~min}$, a denaturation step at $95^{\circ} \mathrm{C}$ for $10 \mathrm{~min}$, then 40 cycles of denaturation at $95^{\circ} \mathrm{C}$ for $15 \mathrm{~s}$ and an annealing/extension step at $60^{\circ} \mathrm{C}$ for $1 \mathrm{~min}$. Emission was measured at the annealingextension step. For each PCR reaction, the cycle threshold $(\mathrm{Ct})$ value, i.e. the number of PCR cycles necessary to increase fluorescence above background, was automatically calculated and analysed by MxPro QPCR Software (version 4.10, Agilent Technologies, USA).

\section{Adrenal and hepatic protein levels}

Adrenal and hepatic tissues were thoroughly rinsed in ice-cold PBS $\left(0.02 \mathrm{mmol} \cdot 1^{-1}, \mathrm{pH} 7.2\right)$ and homogenized in $1 \mathrm{ml}$ (adrenals) or $7 \mathrm{ml}$ (livers) of PBS (with Protease Inhibitor Cocktail Set I, AnimalFree; Calbiochem ${ }^{\circledR}$ ) using a manual glass homogenizer (adrenals) or an electric homogenizer $(7 \times 95 \mathrm{~mm}$ generator, PRO Scientific Inc. Oxford, UK) (livers) on ice. The resulting suspension was subjected to two freezethaw cycles to further break the cell membranes and the homogenates were centrifuged for $5 \mathrm{~min}$ at $5000 \mathrm{~g}$. The supernatants were removed, aliquoted and stored at $-80^{\circ} \mathrm{C}$ for further analysis. Levels of adrenal and liver markers were expressed per milligram adrenal (CYP11B1) or liver (11ß-HSD1, GRs, DIO1 and DIO3) homogenate protein as determined by the microtitred Bradford method (1.10306. BIOQUANT, MERCK, Germany) with bovine serum albumin (SIGMA-ALDRICH, USA) as the standard.

Commercial rat ELISA kits (USCN Life Science Inc., China) were used to estimate adrenal 
CYP11B1 (Enzyme-linked Immunosorbent Assay Kit for Cytochrome P450 11B1 (CYP11B1)) and liver $11 \beta$-HSD 1 (Enzyme-linked immunosorbent assay kit for $11 \beta$-Hydroxysteroid Dehydrogenase Type 1 (11ß-HSD1)), GR (Enzyme-linked Immunosorbent assay kit for rat glucocorticoid receptor (GR), DIO1 (Enzyme-linked Immunosorbent Assay Kit for Deiodinase, Iodothyronine, type 1 (DIO1)), and DIO3 (Enzyme-linked immunosorbent assay kit for deiodinase, iodothyronine, type 3 (DIO3)) protein levels. The sensitivities of the applied tests were less than $0.135 \mathrm{ng} \cdot \mathrm{ml}^{-1}, 0.128 \mathrm{ng} \cdot \mathrm{ml}^{-1}$, $0.051 \mathrm{ng} \cdot \mathrm{ml}^{-1}, 0.055 \mathrm{ng} \cdot \mathrm{ml}^{-1}$, and $0.117 \mathrm{ng} \cdot \mathrm{ml}^{-1}$, respectively. Intra- and interassay precisions were $\mathrm{CV}$ $<10 \%$ and $\mathrm{CV}<12 \%$, respectively, for all assay kits.

\section{Plasma hormone concentrations}

A commercial ELISA kit (adrenocorticotropic hormone, ACTH ELISA Kit; USCN Life Science Inc., China) was used to estimate plasma ACTH concentrations. Plasma corticosterone concentrations were determined by a commercial RIA kit (Izotop, Institute of Isotopes Co., Ltd., Hungary). Intra- and interassay precisions stood at $\mathrm{CV}=1.7 \%$ and $\mathrm{CV}=4.4 \%$, respectively.

\section{Statistical analyses}

Results are reported as means \pm SEM. Data were compared (effects of calorie restriction and rat age) by two-way analysis of variance (ANOVA) for normal distribution and the Kruskal-Wallis ANOVA test for abnormal distribution, followed by the post-hoc LSD Fisher's test. Correlations between variables concerned were assessed by means of the Pearson and the Spearman correlation methods, respectively. Statistical significance was accepted for $P<0.05$. All statistical analyses were performed using the Statistica v. 10 software package (StatSoft, USA).

\section{Results}

\section{Body weight and energy intake}

In younger AL rats, body weight (BW) increased linearly up to the seventh week of the experiment, and then declined during the last week of the experiment. The body weight gain of younger R20 rats showed successive retardation up to the third week of the experiment, it stabilized afterwards to increase again after the next two weeks, and remained unchanged between the seventh and the eighth week of the experiment. The BW of younger R40 rats showed a significant decrease between the first and the third week of the experiment, and thereafter remained unchanged (Figure 1A).
In older BL rats, BW remained unchanged throughout the experiment, whereas older R20 rats showed successive growth retardation up to the fifth week, and thereafter their body weight stabilized. At the same time, R40 rats showed successive growth retardation up to the end of the experiment (Figure 1B).
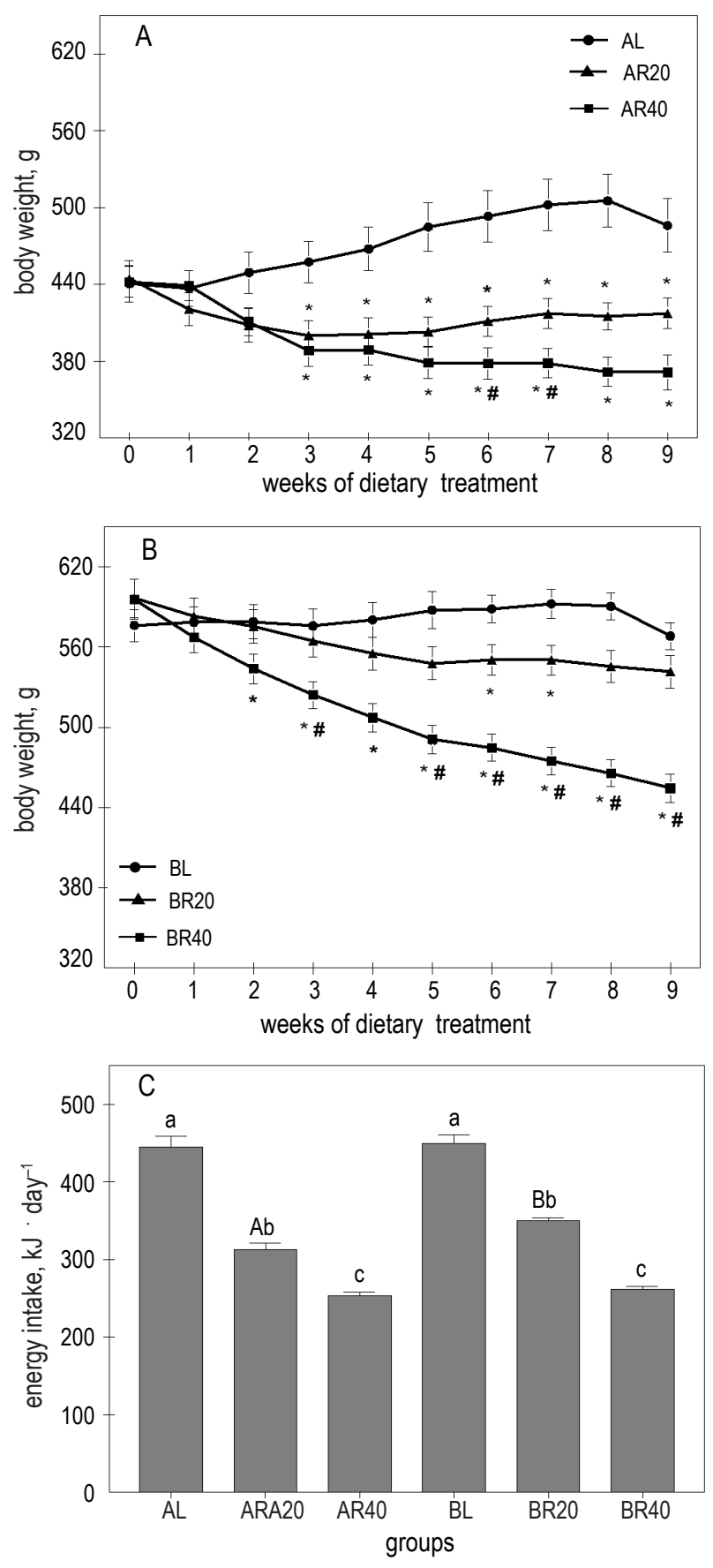

Figure 1. Changes in body weight in younger (A) and older animals (B), energy intake $(C)$ in groups: $L$ (fed ad libitum), R20 ( $80 \%$ of energy intake of $L$ ) and R40 (60\% of energy intake of $L$ ). Statistical analyses: *denotes significant difference between L and R20 or R40; " denotes significant difference between R20 and R40; different lower case letters indicate significant differences within younger and older groups $(P<0.05)$, different upper case letters indicate significant differences between younger and older groups $(P<0.05)$ 
Energy intake was influenced by both energy restriction level and age $(P<0.00001$ and $P<0.016$, respectively), with the highest values in groups $\mathrm{AL}$ and BL and the lowest, in groups AR40 and BR40. Moreover, in the case of the R20 groups, energy intake was lower in younger rats than in older ones (Figure 1C).

\section{Plasma hormone concentrations}

The plasma ACTH concentration was influenced by feeding level $(P<0.05)$ and age $(P<0.013)$. Plasma ACTH was significantly higher in the R40 group than in the AL/BL and R20 groups, both in younger and older rats. In older rats, plasma ACTH concentrations were higher than in their younger counterparts (Figure 2A).

Plasma Cs levels were found to be dependent only on feeding level $(P<0.003)$. However, Cs levels in groups R20 and R40 were significantly higher than in the AL groups only in older rats (Figure 2B).

\section{Adrenal CYP11B1 mRNA and protein levels}

The adrenal CYP11B1 mRNA level was not affected by feeding level or age (Figure $3 \mathrm{~A}$ ). The CYP11B1 protein level, however, was found to depend on age and feeding level $(P<0.00005$ and $P<0.02$, respectively). In younger rats, CYP11B1

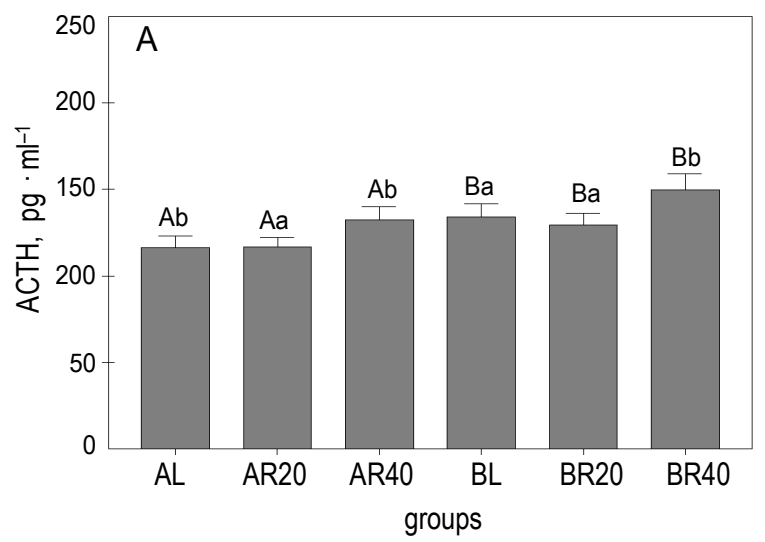

protein was not affected by feeding, whereas in older R20 rats, the CYP11B1 protein level was higher than in AL rats. In addition, the CYP11B1 protein level was lower in younger R20 and R40 rats, as compared with the respective older groups (Figure 3B).

\section{Liver GR and 11ß-HSD1 protein levels}

Liver GR protein levels were not affected by feeding level, but GRs were found to be dependent on age $(P<0.02)$ and to be significantly higher in younger R40 rats than in the respective older group $(P<0.04$; Figure 4A).

The 11 $\beta$-HSD1 protein level was dependent on feeding level $(P<0.05)$, but a significant effect was observed only in older rats. In older BL and R20 groups, the 11 $\beta$-HSD1 protein level was higher than in the R40 groups (Figure 4B). Glucocorticoid receptor and $11 \beta$-HSD 1 protein levels correlated positively in both younger rats $(R=0.61 ; P<0.005)$ and in older ones $(R=0.51 ; P<0.015$; Figures $5 \mathrm{~A}$ and $5 \mathrm{~B}$ ).

\section{Liver DIO1 and DIO3 protein levels}

The liver DIO1 protein level was not affected by feeding level, but was found to be dependent on age $(P<0.04)$. Type 1 deiodinase protein was higher in younger rats than in older ones, but only in the

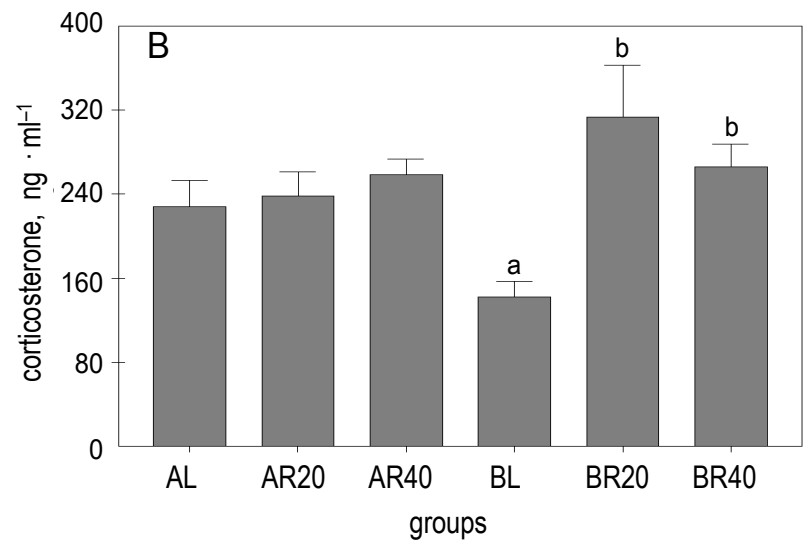

Figure 2. Plasma ACTH (A) and corticosterone (B) concentrations. Explanations as described in the title of Figure 1
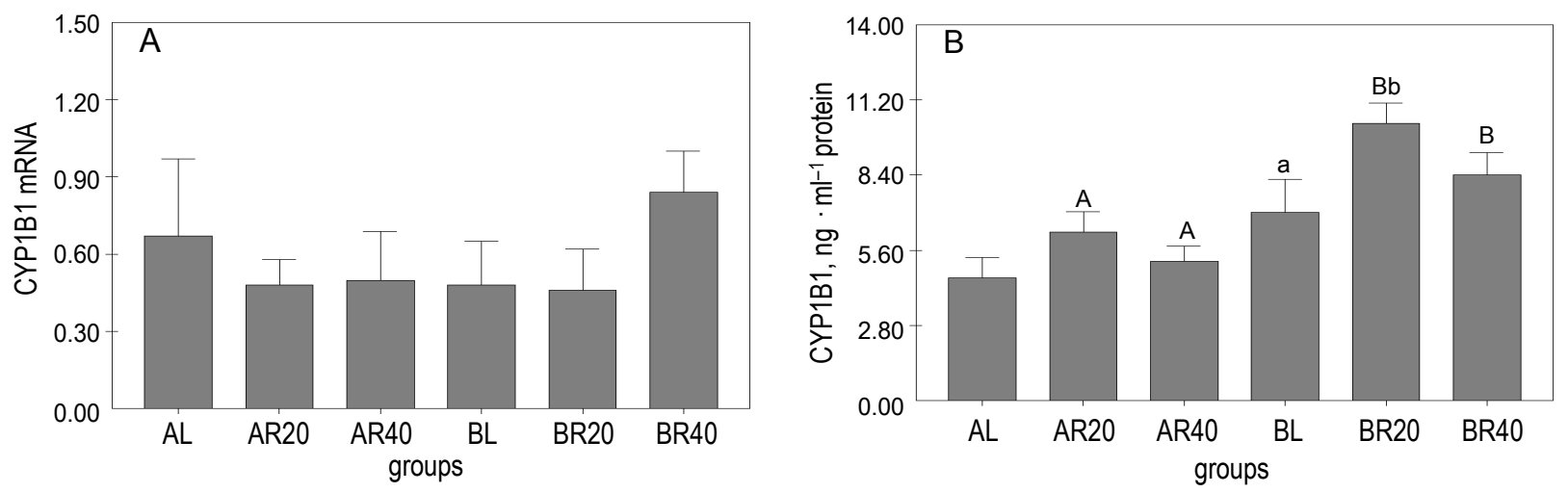

Figure 3. Adrenal CYP11B1 (A) mRNA and CYP11B1 protein level (B). Explanations as described in the title of Figure 1 

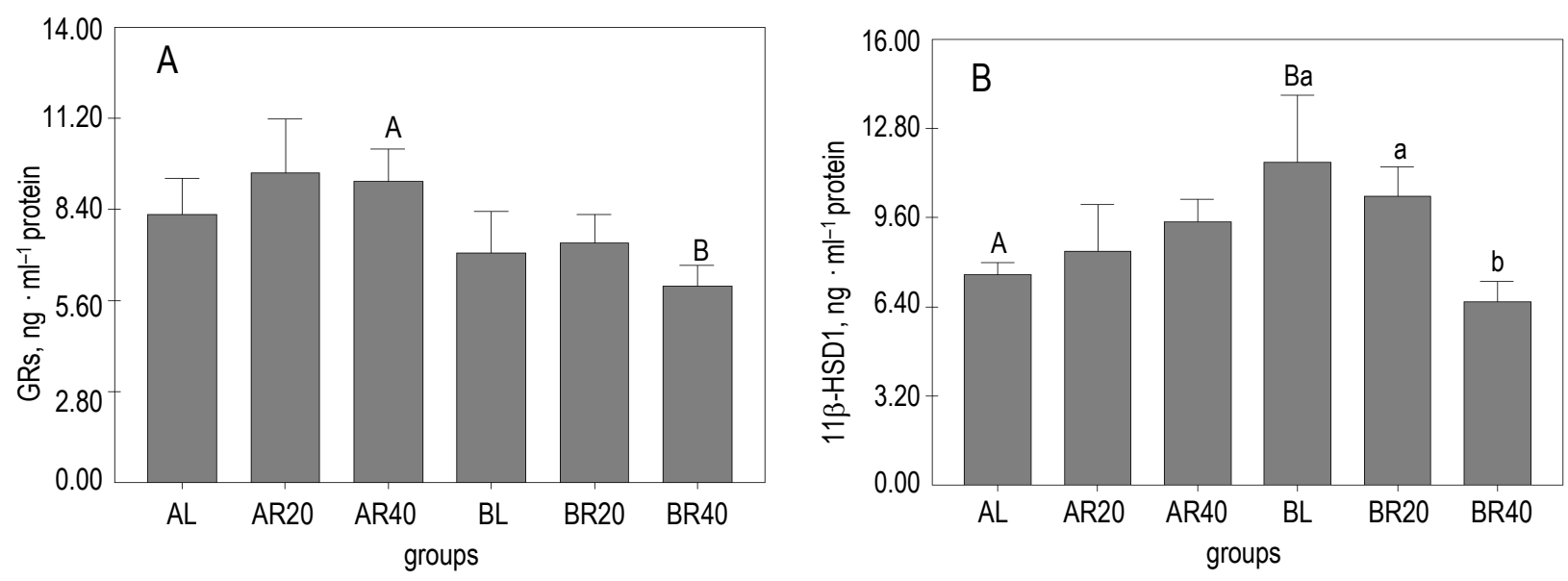

Figure 4. Liver GRs (A) and 11ß-HSD1 (B) protein levels. Explanations as described in the title of Figure 1
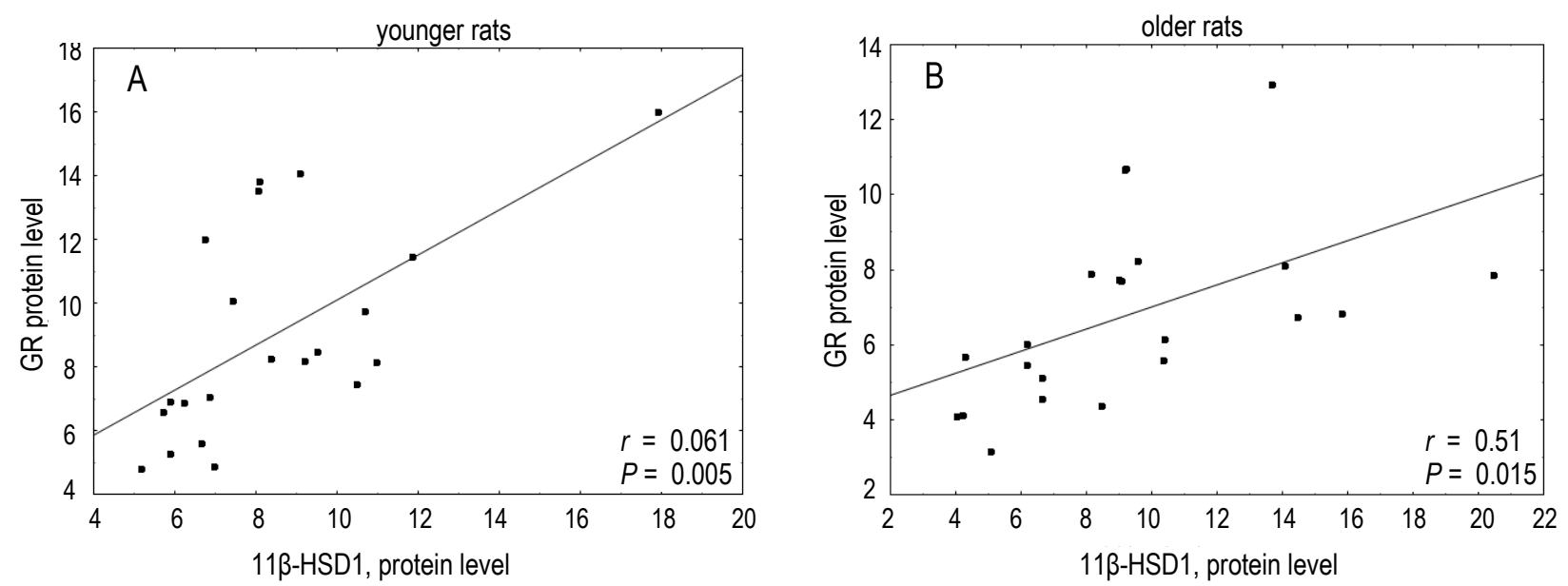

Figure 5. Correlations between GR and 11 $\beta-H S D 1$ protein levels in younger $(A)$ and older $(B)$ rats
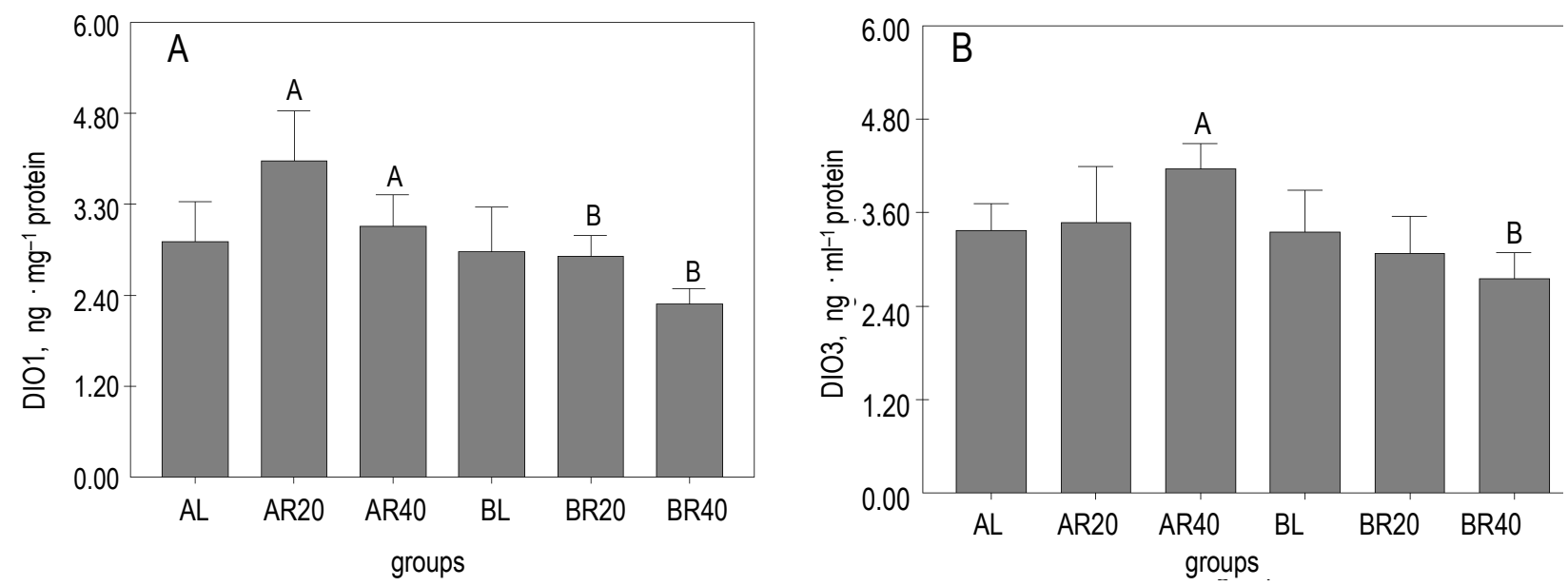

Figure 6. Liver DIO1 (A) and DIO3 (B) protein levels. Explanations as described in the title of Figure 1

calorie-restricted groups (Figure 6A). The type 3 deiodinase protein level was not affected by either feeding level or age. In younger R40 rats, however, DIO3 protein was higher than in older R40 rats $(P<0.03$; Figure 6B).

The type 1 deiodinase protein level was directly related to GRs protein both in younger rats $(r=0.77 ; P<0.0001)$ and in older ones $(r=0.44$;
$P<0.04)$. Type 3 deiodinase protein levels were also directly related to GR protein both in younger rats $(r=0.6 ; P<0.017)$ and in older ones $(r=0.9$; $P<0.00001$; Figures 7A and 7B). Moreover, liver DIO3 protein levels were positively correlated with the liver $11 \beta$-HSD1 protein level in younger rats $(r=0.78 ; P<0.0007)$ and in older animals $(r=0.73$; $P<0.0014$; Figures $8 \mathrm{~A}$ and $8 \mathrm{~B}$ ). 

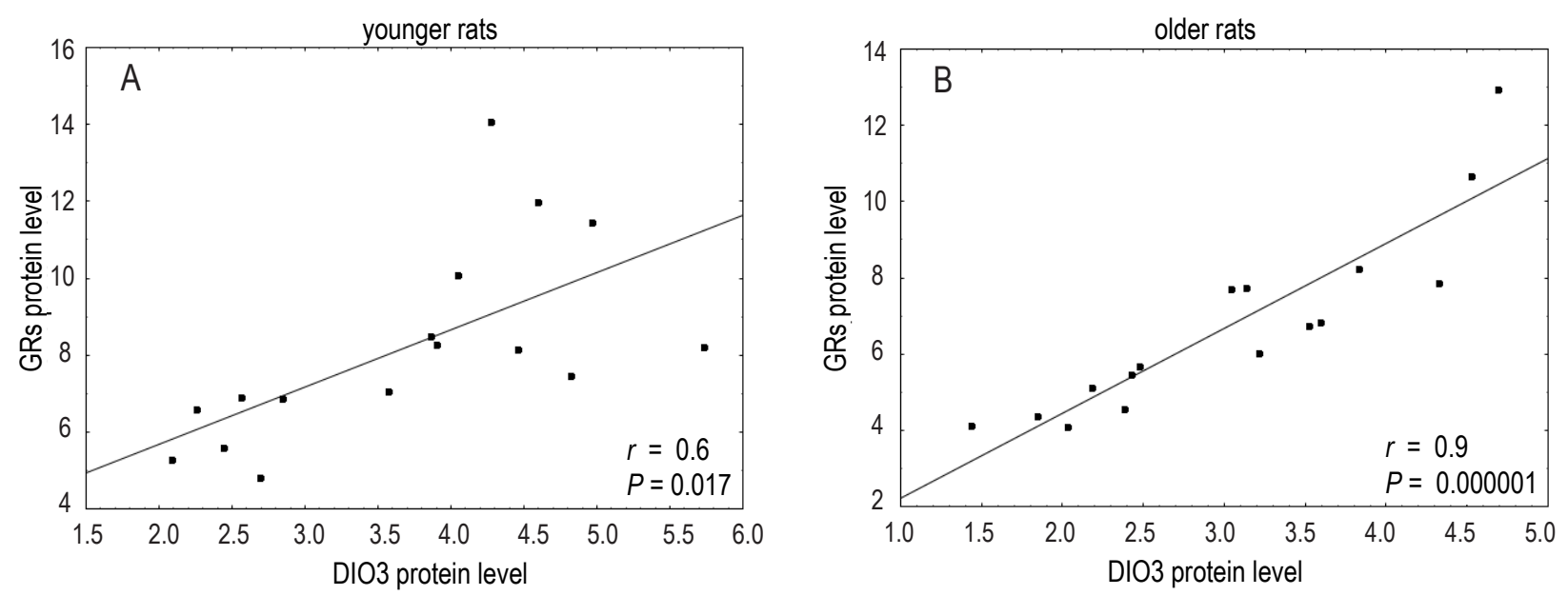

Figure 7. Correlations between GRs and DIO3 protein levels in younger (A) and older (B) rats
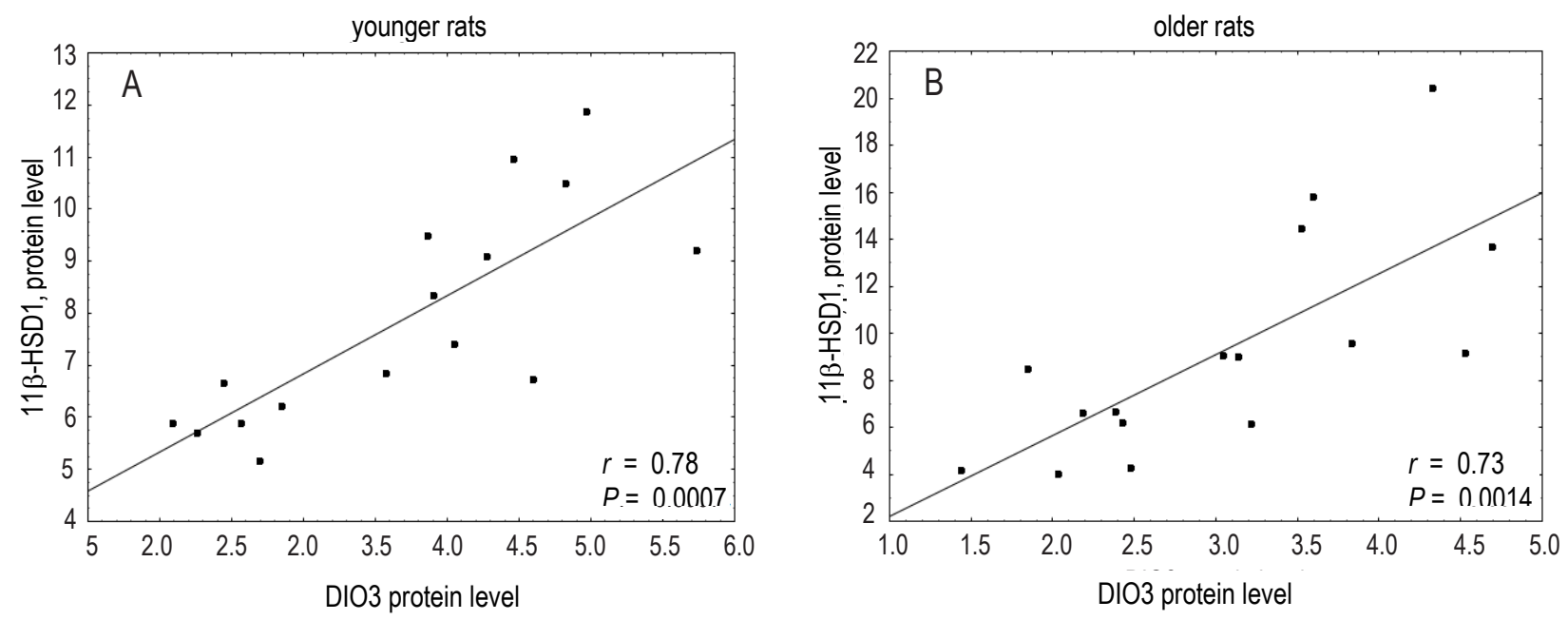

Figure 8. Correlations between $11 \beta$-HSD1 and DIO3 protein levels in younger $(A)$ and older $(B)$ rats

\section{Discussion}

Calorie and food restriction have been shown to increase hypothalamus-pituitary-adrenal (HPA) axis activity, as shown by, among others, augmented CRH mRNA in the hypothalamic paraventricular nucleus and plasma ACTH and GC concentrations (Johnstone et al., 2004; Belda et al., 2005; Tomiyama et al., 2010; Milošević et al., 2011; Guarnieri et al., 2012). In our study, the response of Cs to calorie restriction appeared to depend on age, since CR evoked an increase in Cs concentrations only in older rats. Although the CR-induced increase in ACTH levels occurred in both age groups, the effect of age on ACTH plasma concentration was expressed by higher ACTH levels in older rats. This corresponds with the adrenal CYP11B1 protein response to the experimental conditions - it was affected by both animal age and feeding level. While the differences in enzyme levels between ad libitum-fed rats were not significant, the increase induced by $\mathrm{CR}$ was higher in older rats. Thus, the CYP11B1 protein level was higher in energy-restricted older rats than in younger ones. Our results show that the responsiveness of adrenal steroidogenesis to CR does not decline with age, unlike adrenal sensitivity to ACTH (Cheng et al., 1990).

Irrespective of age, we did not observe any significant effect of CR on hepatic GRs, despite the key role of GRs in liver metabolic regulation under conditions of energy restriction such as exercise, fasting and starvation governed by the increase in systemic Cs concentrations. Hepatic GRs coordinate changes in metabolism leading to an increase in hepatic glucose production, synthesis of fatty acids and triglycerides. Glucocorticoid receptors directly control more than 50 genes connected with hepatic energy metabolism (Phuc Le et al., 2005). Hepatic GRs levels have been shown to increase in mice subjected to alternate day fasting for three months, as compared 
with those fed ad libitum (Dutta and Sharma, 2003). It was calculated that rats and mice maintained on such an alternate day feeding schedule consumed approximately $30 \%$ of the feed offered to animals fed ad libitum for three months (Lee et al., 2000). Thus, the absence of a statistically significant response of GR levels to CR in our study could result from smaller energy deficits minus $20 \%$ and $40 \%$, and, on the other hand, from calorie restriction only, not whole feed intake restriction. In our experiment, liver glucocorticoid receptor levels were higher in six-month-old rats than in older 12-monthold ones. The results concerning the effect of aging on GR quantity are equivocal. No differences in hepatic GR concentrations were found between 12- and 28-month-old male Wistar rats (Dellwo and Beauchene, 1990), i.e. in animals older than in our experiment. On the other hand, a lower renal GR concentration was found in 20-month-old fed mice as compared with 5-month-old mice. Interestingly, dietary restriction (feeding the animals on alternate days for three months) upregulated liver GRs in older mice (Sharma and Dutta, 2006). Lower GR concentrations were also observed in the livers of old 120-week-old mice, as compared with young 4-week-old ones (Ranhotra and Sharma, 2001). The results of the study by Spindler et al. (1991) performed in male and female mice point to the dependence of the effect of aging on mice gender. An aging-related increase in liver GR mRNA occurred only in female mice fed both ad libitum and energyrestricted (minus 20\% and 52\% energy) diets. The above results imply that the effect of aging on GR levels could depend on tissue, species strain and gender, as well as on period of life.

The biological activity of glucocorticoids can be affected not only by the number and affinity of GRs, but also by the concentration and tissue activity of $11 \beta$-HSD1. Despite the absence, according to ANOVA, of a significant effect of age in the entire group studied, a markedly higher enzyme level was observed in older AL rats than in the respective younger animals. Several studies have demonstrated an age-related increase in 11 $\beta$-HSD1 expression and activity in different tissues. Age-associated increases in 11 $\beta$-HSD1 mRNA in the mouse brain cortex and hippocampus have been observed in 24-27-month-old mice, as compared with 6-monthold ones (Holmes et al., 2010). A direct relation between $11 \beta$-HSD1 activity and age was reported in human primary osteoblasts (Cooper et al., 2000) and human skin explants (Tiganescu et al., 2010). This corresponds with higher plasma ACTH and Cs, and the adrenal CYP11B1 levels observed in older rats corroborate previous data indicating the age-associated increase in HPA activity.

Our results show an effect of CR on the hepatic $11 \beta-H S D 1$ protein concentration, observed, however, only in older rats. The energy deficit evoked a fall in 11 $\beta$-HSD1 protein, i.e. the liver enzyme level was significantly lower in B40 than in B20 and BL. Similarly, a drop in 11ß-HSD1 mRNA in omental adipose tissue was already observed after two days of $20 \%$ feed restriction, but the differences disappeared after 14 days of treatment (Arai et al., 2004). It is noteworthy that the changes in the $11 \beta$-HSD1 concentration observed in our study were opposite to the CR-evoked changes in plasma ACTH and Cs concentrations in older rats. Nonetheless, the direct relationship between 11 $\beta$-HSD1 and GRs suggests the possibility of persistence of relationships between Cs and 11 $\beta-H S D 1$, although at an altered set point, and corroborates the role of $11 \beta-H S D 1$ in intracellular Cs supply. On the other hand, taking into consideration the putative connection of $11 \beta$-HSD1 with the pathogenesis of type 2 diabetes, atherosclerosis, inflammation and osteoporosis, a decrease in type $111 \beta-H S D$ expression and protein level induced by caloric restriction could be beneficial in the prophylaxis of those diseases.

In our study, type 1 deiodinase was affected by age only, and was higher in younger rats, whereas DIO3 did not depend on experimental conditions. We have not found previous reports on the effect of age on DIO1 or DIO3 liver expression. In our experiment, however, we observed a higher plasma fT3 concentration in younger rats, which could reflect higher DIO1 activity in this group (Lachowicz et al., 2014). On the other hand, rodent liver DIO1 activity was reduced by $40 \%$ calorie restriction introduced for 30 days (Araujo et al., 2008) or for 25 days (Araujo et al., 2009) and by 24-h fasting (Aceves et al., 2003), or was not changed by 24 -h fasting (Boelen et al., 2012), while DIO1 mRNA remained unaffected by 24-h fasting (Aceves et al., 2003; Boelen et al., 2012). On the other hand, an increase in liver DIO3 mRNA expression was found after 24-h fasting (Boelen et al., 2012).

Despite the lack of significant effects of CR on DIO1, DIO2 and GRs, we found a strong, direct relationship between liver GRs and DIO3, and a weaker positive correlation between liver GRs and DIO1 in both age groups of rats. Decreases in plasma T4 and T3 levels following dexamethasone treatment have been reported previously in humans (Chopra et al., 1975; Williams et al., 1975; 
Degroot and Hoye, 1976; Maes et al., 1990), chicken (Darras et al., 1996), ewes (Forhead et al., 2007) and dogs (Gottschalk et al., 2011), together with a rise in plasma rT3 (Chopra et al., 1975; LoPresti et al., 1989; Maes et al., 1990; Forhead et al., 2007). An increase in rT3 reflects augmentation of 5 deiodination activity which can result from both an increase in DIO3 activity and a change in DIO1 activity from outer- to innerring iodothyronine deiodination. Despite the effects reported above, glucocorticosteroids have been shown to induce DIOI mRNA expression in rat hepatocytes (Menjo et al., 1993; Davies et al., 1996) and kidney cells (Davies et al., 1996). Dexamethasone and T3 exerted a synergistic effect on DIO1 in pituitary tumour cells (Maia et al., 1995). Type 3 deiodinase expression has been shown to be downregulated by glucocorticosteroids in rat brown fat vascular stromal cells (Hernandez and St. Germain, 2002). Dexamethasone treatment exerted differentiated effects on circulating THs and DIO1, and DIO3 activities in rats depending on the stage of development and tissue. In liver and kidney, dexamethasone augmented DIO3 and did not change DIO1 activity on the $5^{\text {th }}$ and $12^{\text {th }}$ day postnatally (Van der Geyten and Darras, 2005). Our results show that direct relationships between hepatic $11 \beta$-HSD1, GRs, DIO1 and DIO3 can be observed under conditions of differentiated energy supply. Changes in GRs and DIO3 proteins in response to alterations in energy supply seem to be especially strongly coupled.

\section{Conclusions}

Calorie restriction (CR) evoked changes in hypothalamus-pituitary-adrenal (HPA) axis activity dependent on age and energy deficit. The increase in HPA activity induced by energy deficit includes a rise in plasma adrenocorticotropic hormone and corticosterone concentrations, as well as adrenal CYP11B1 protein levels. In contrast with the foregoing, hepatic 11 $\beta$-HSD1 protein was reduced in $\mathrm{CR}$ rats. Glucocorticoid receptor protein and DIO3 protein were strongly positively correlated, which implies a mechanism coupling an increase in GCs receptors with the diminishing of thyroid hormone action resulting from a switch to rT3 production.

\section{Acknowledgements}

This work was supported by the Ministry of Science and Higher Education of Poland, Grant No. NN 312379037.

\section{References}

Aceves C., Escobar C., Rojas-Huidobro R., Vázquez-Martínez O., Martínez-Merlos T., Aguilar-Roblero R., Díaz-Muñoz M., 2003. Liver 5'-deiodinase activity is modified in rats under restricted feeding schedules: evidence for post-translational regulation. J. Endocrinol. 179, 91-96

Adcock I.M., Caramori G., Ito K., 2006. New insights into the molecular mechanisms of corticosteroids actions. Curr. Drug Targets 7, 649-660

Aguilera G., 2011. HPA axis responsiveness to stress: implications for healthy aging. Exp. Gerontol. 46, 90-95

Arai K., Soga T., Ohata H., Otagiri A., Shibasaki T., 2004. Effects of food restriction on peroxisome proliferator-associated receptor-y and glucocorticoid receptor signaling in adipose tissues of normal rats. Metabolism 53, 28-36

Araujo R.L., Andrade B.M., Figueiredo A.S., da Silva M.L., Marassi M.P., Pereira Vdos S., Bouskela E., Carvalho D.P., 2008. Low replacement doses of thyroxine during food restriction restores type I deiodinase activity in rats and promotes body protein loss. J. Endocrinol. 198, 119-125

Araujo R.L., Andrade B.M., da Silva M.L., Ferreira A.C., Carvalho D.P., 2009. Tissue-specific deiodinase regulation during food restriction and low replacement dose of leptin in rats. Amer. J. Physiol.-Endocrinol. Met. 296, E1157-E1163

Auvinen H.E., Romijn J.A., Biermasz N.R., Pijl H., Havekes L.M., Smit J.W.A., Rensen P.C.N., Pereira A.M., 2012. The effects of high fat diet on the basal activity of the hypothalamus-pituitary-adrenal axis in mice. J. Endocrinol. 214, 191-197

Belda X., Ons S., Carrasco J., Armario A., 2005. The effects of chronic food restriction on hypothalamic-pituitary-adrenal activity depend on morning versus evening availability of food. Pharmacol. Biochem. Behav. 81, 41-46

Bianco A.C., Salvatore D., Gereben B., Berry M.J., Larsen P.R., 2002. Biochemistry, cellular and molecular biology, and physiological roles of the iodothyronine selenodeiodinases. Endocrine Rev. 23, 38-89

Boelen A., van Beeren M., Vos X., Surovtseva O., Belegri E., Saaltink D.J., Vreugdenhil E., Kalsbeek A., Kwakkel J., Fliers E., 2012. Leptin administration restores the fasting-induced increase of hepatic type 3 deiodinase expression in mice. Thyroid 22, 192-199

Cheng B., Horst I.A., Mader S.L., Kowal J., 1990. Diminished adrenal steroidogenic activity in aging rats: new evidence from adrenal cells culterued from young and aged normal and hypoxic animals. Mol. Cell. Endocrinol. 73, R7-R12

Chopra I.J., Williams D.E., Orgiazzi J., Solomon D., 1975. Opposite effects of dexamethasone on serum concentrations of 3,3', 5'-triiodothyronine (reverse T3) and 3,3',5-triiodothyronine (T3). J. Clin. Endocrinol. Metab. 41, 911-920

Cooper M.S., Walker E.A., Bland R., Fraser W.D., Hewison M., Stewart P.M., 2000. Expression and functional consequences of 11 beta-hydroxysteroid dehydrogenase activity in human bone. Bone 27, 375-381

Darras V.M., Kotanen S.P., Geris K.L., Bergham L.R., Kühn E.R., 1996. Plasma thyroid hormone levels and iodothyronine deiodinase activity following an acute glucocorticoid challenge in embryonic compared with posthatch chickens. Gen. Comp. Endocrinol. 104, 203-212

Davies P.H., Sheppard M.C., Franklyn J.A., 1996. Regulation of type I 5 '-deiodinase by thyroid hormone and dexamethasone in rat liver and kidney cells. Thyroid 6, 221-228

Degroot L.J., Hoye K., 1976. Dexamethasone suppression of serum T3 and T4. J. Clin. Endocrinol. Metab. 42, 976-978 
Dellwo M., Beauchene R.E., 1990. The effects of exercise, diet restriction, and aging on the pituitary-adrenal axis in the rat. Exp. Gerontol. 25, 553-562

Dutta D., Sharma R., 2003. Regulation of hepatic glucocorticoid receptors in mice during dietary restriction. Hormone Metab. Res. $35,415-420$

Fernando H.A., Chin H.-F., Ton S.H., Kadir K.A., 2013. Stress and its effects on glucose metabolism and 11ß-HSD activities in rats fed on a combination of high-fat and high-sucrose diet with glycyrrhizic acid. J. Diabetes Res. http://dx.doi. org/10.1155/2013/190395

Forhead A.J., Jellyman J.K., Gardner D.S., Giussani D.A., Kaptein E., Visser T.J., Fowden A.L., 2007. Differential effects of maternal dexamethasone treatment on circulating thyroid hormone concentrations and tissue deiodinase activity in the pregnant ewe and fetus. Endocrinology 148, 800-805

Gottschalk J., Einspanier A., Ungemach F.R., Abraham G., 2011. Influence of topical dexamethasone applications on insulin, glucose, thyroid hormone and cortisol levels in dogs. Res. Vet. Sci. 90, 491-497

Guarnieri D.J., Brayton C.E., Richards S.M., Maldonado-Aviles J., Trinko J.R., Nelson J., Taylor J.R., Gourley S.L., DiLeone R.J., 2012. Gene profiling reveals a role for stress hormones in the molecular and behavioral response to food restriction. Biol. Psychol. 71, 358-365

Hernandez A., St. Germain L., 2002. Dexamethasone inhibits growth factor-induced type 3 deiodinase activity and mRNA expression in a cultured cell line derived from rat neonatal brown fat vascular-stromal cells. Endocrinology 143, 2652-2658

Holmes M.C., Carter R.N., Noble J., Chitnis S., Dutia A., Paterson J.M., Mullins J.J., Seckl J.R., Yau J.L.W., 2010. 11ß-Hydroxysteroid dehydrogenase type 1 expression is increased in the aged mouse hippocampus and parietal cortex and causes memory impairments. J. Neurosci. 30, 6916-6920

Johnstone A.M., Faber P., Andrew R., Gibney E.R., Elia M., Lobley G., Stubbs R.J., Walker B.R., 2004. Influence of short-term dietary weight loss on cortisol secretion and metabolism in obese men. Eur. J. Endocrinol. 150, 185-194

Kharwanlang B., Sharma R., 2011. Molecular interaction between the glucocorticoid receptor and MAPK signalling pathway: a novel link in modulating the anti-inflammatory role of glucocorticoids. Indian J. Biochem. Biophys. 48, 236-242

Lachowicz K., Fürstenberg E, Pałkowska E., Stachoń M., Gajewska D., Myszkowska-Ryciak J., Kozłowska L., Ciecierska A., Rosołowska-Huszcz D., 2014. Effect of caloric restriction and age on thyroid hormone signalling in the heart. J. Food Anim. Sci. 23, 97-104

Lee J., Herman J.P., Mattson M.P., 2000. Dietary restriction selectively decreases glucocorticoid receptor expression in the hippocampus and cerebral cortex of rats. Exp. Neurol. 166, 435-441

LondonE., Castonguay T.W., 2009. Dietand the role of $11 \beta$-hydroxysteroid dehydrogenase-1 on obesity. J. Nutr. Biochem. 20, 485-493

London E., Castonguay T.W., 2011. High fructose diets increase $11 \beta$-hydroxysteroid dehydrogenase type 1 in liver and visceral adipose in rats within 24-h exposure. Obesity 19, 925-932

LoPresti J.S., Eigen A., Kaptein E., Anderson K.P., Spencer C.A., Nicoloff J.T., 1989. Alterations in 3,3',5'-triiodothyronine metabolism in response to propylthiouracyl, dexamethasone, and thyroxine administration in man. J. Clin. Invest. 84, 1650-1656

Maes M., Vandewoude M., Schotte C., Martin M., Blockx P., 1990. Suppressive effects of dexamethasone on hypothalamicpituitary-thyroid axis function in depressed patients. J. Affect. Disorders 20, 55-61
Maia A.L., Harney J.W., Larsen P.R., 1995. Pituitary cells respond to thyroid hormone by discrete, gene-specific pathways. Endocrinology 136, 1488-1494

Menjo M., Murata Y., Fujii T., Nimura Y., Seo H., 1993. Effects of thyroid and glucocorticoid hormones on the level of messenger ribonucleic acid for iodothyronine type I 5'-deiodinase in rat primary hepatocytes grown as spheroids. Endocrinology 133, 2984-2990

Milošević V.L.J., Ajdžanović V.Z., Bogojević D.B., Medigović I.M., Ivanović-Matić S.K., Martinović V.I., Grigorov I.I., 2011. The effect of chronic food restriction on immunopositive ACTH cells in peripubertal female rats. Gen. Physiol. Biophys. 30, 321-324

Morton N.M., Ramage L., Seckl J.R., 2004. Down-regulation od adipose $11 \beta$-hydroxysteroid dehydrogenase type 1 by high-fat feeding in mice: a potential adaptive mechanism counteracting metabolic disease. Endocrinology 145, 2707-2712

Phuc Le P., Friedman J.R., Schug J., Brestelli J.E., Parker J.B., Bochkis I.M., Kaestner K.H., 2005. Glucocorticoid receptor-dependent gene regulatory networks. PLoS Genet. 1, e16

Ranhotra H.S., Sharma R., 2001. Modulation of hepatic and renal glucocorticoid receptors during aging of mice. Biogerontology 2, 245-251

Rask E., Simonyte L., Axelson M., 2013. Cortisol metabolism after weight loss: associations with $11 \beta$-HSD type 1 and markers of obesity in women. Clin. Endocrinol. 78, 700-705

Seckl J.R., 2004. 11ß-hydroxysteroid dehydrogenases: changing glucocorticoid action. Curr. Opin. Pharmacol. 4, 597-602

Sewer M.B., Dammer E.B., Jagarlapudi S., 2007. Transcriptional regulation of adrenocortical steroidogenic gene expression. Drug Metab. Rev. 39, 371-388

Sharma R., Dutta D., 2006. Age-dependent decrease in renal glucocorticoid receptor function is reversed by dietary restriction in mice. Ann. NY Acad. Sci. 1067, 129-141

Simonyte K., Olsson T., Näslund I., Angelhed J.E., Lönn L., Mattsson C., Rask E., 2010. Weight loss after gastric bypass surgery in women is followed by a metabolically favorable decrease in 11 beta-hydroxysteroid dehydrogenase 1 expression in subcutaneous adipose tissue. J. Clin. Endocrinol. Metab. 95, 3527-3531

Spindler S.R., Grizzle J.M., Walford R.L., Mote P.L., 1991. Aging and restriction of dietary calories increases insulin receptor mRNA, and aging increases glucocorticoid receptor mRNA in the liver of female C3B10RF1 mice. J. Gerontol. 46, B233-237

Tiganescu A., Walker E.A., Hardy R.S., Mayes A.E., Stewart P.M., 2011. Localization, age- and site-dependent expression, and regulation of $11 \beta$-hydroxysteroid dehydrogenase type 1 in skin. J. Invest. Dermatol. 131, 30-36

Tomiyama A.J., Mann T., Vinas D., Hunger J.M., Dejager J., Taylor S.E., 2010. Low calorie dieting increases cortisol. Psychosom. Med. 72, 357-364

Tomlinson J.W.., Walker E.A., Bujalska I.J., Draper N., Lavery G.G., Cooper M.S., Hewison M., Stewart P.M., 2004. $11 \beta$-hydroxysteroid dehydrogenase type 1: a tissue-specific regulator of glucocorticoid response. Endocrine Rev. 25, 831-866

Van der Geyten S., Darras V.M., 2005. Developmentally defined regulation of thyroid hormone metabolism by glucocorticoids in the rat. J. Endocrinol. 185, 127-1376

Williams D.E., Chopra I.J., Orgiazzi J., Solomon D.H., 1975. Acute effects of corticosteroids on thyroid activity in Graves' disease. J. Clin. Endocrinol. Metab. 45, 354-361 